\title{
Congenital Pulmonary Airway Malformation Type 2: A Case Report with Review of the Literature
}

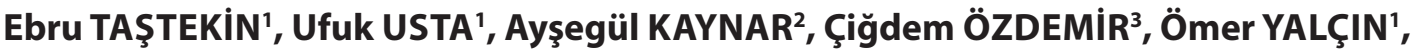 \\ Filiz ÖZYILMAZ' ${ }^{\text {, Ali Kemal KUTLU' }}$
}

Department of Pathology, 'Trakya University, Faculty of Medicine, EDIRNE, TURKEY, ${ }^{2}$ Iskenderun State Hospital, HATAY, TURKEY and

${ }^{3}$ Tekirdag State Hospital, TEKIRDAĞ, TURKEY

\begin{abstract}
A congenital pulmonary airway malformation is a rare disorder of the pulmonary airway and a hamartomatous mass of disorganized lung tissues with various degrees of cystic change. A 20 -year-old pregnant woman who did not have previous clinical follow-up during her pregnancy visited the gynecology department for her first check on the 19th week of gestation. The sonogram, showed severe hydrops fetalis. Laboratory findings were consistent with non-immune hydrops fetalis. Medical abortion was performed and the fetus was sent to our department for a complete fetal autopsy. Macroscopically, whole parts of the fetus had striking oedema. Massive pleural and peritoneal effusions were seen on dissection. The left lung filled the whole thoracic cavity. The heart was displaced to the right and the right lung was compressed. Microscopically, the left lung mass showed dilated bronchiole-like structures $(1-20 \mathrm{~mm})$ that were lined with ciliated columnar cells without any intervening mucinous cells. The subepithelial stroma contained thin, interrupted smooth muscle fibers and elastic connective tissue without cartilage plates. Our case is a very good example of non-immune hydrops fetalis associated with congenital pulmonary airway malformation type 2 . Prenatal clinical and ultrasonographic follow-ups during pregnancy are very important for early diagnosis of congenital malformations.
\end{abstract}

Key Words: Cystic adenomatoid malformation of lung, Congenital, Lung diseases, Hydrops fetalis

\section{INTRODUCTION}

Congenital pulmonary airway malformation (CPAM) of the pulmonary airway is an unusual lesion, combining features of hamartoma, malformation or dysplastic proliferation. CPAM was first described using the past terminology of congenital cystic adenomatoid malformation by Ch'in and Tang in 1949 (1-3). Stocker (4) suggested an expanded classification renaming this group of malformations as congenital pulmonary airway malformation (CPAM). There are five types. Only one of the types (type 3) is adenomatoid and only three (types 1,2 and 4) are cystic. CPAM is quite rare and the etiology and incidence are unknown (5). However CPAM represents about $25 \%$ of all congenital lung lesions. In the literature, male and female populations are affected equally. Lower lobe lesions predominate with $44 \%$ of all cases while the rest of the cases are scattered in other lobes and is primarily unilateral, but may also occur bilaterally (6). Associated findings in CPAMs are polyhydramnios, pleural effusion and rarely non-immune fetal hydrops (7).

CPAM is characterized by the lack of normal alveoli, an excessive proliferation and cystic dilatation of terminal

(Turk Patoloji Derg 2016, 32:200-204)

Received : 02.10.2011 Accepted : 23.07.2012 respiratory bronchioles with various types of epithelial lining. Microscopically the cyst linings are composed of ciliated, cuboidal or columnar cells and those cysts have lack of normal architecture and are frequently devoid of cartilage (8). Type 2 CPAM that is associated with other congenital anomalies is seen more frequently than other types (2). We report a fetal autopsy case of type 2 CPAM with an unusual combination of accompanying extra pulmonary abnormalities with prenatal diagnosis at the 19th week of gestation.

\section{CASE REPORT}

A 20-year-old woman who did not have previous clinical follow-up during her pregnancy was referred to the gynecology department for her first control at the 19th week of gestation. The ultrasonogram (USG) showed severe hydrops fetalis with other sonographic abnormalities including a large mediastinal mass filling the left thoracic cavity, causing the mediastinal shift, displacing the heart to the right side, and compressing the right lung, vena cava superior and vena cava inferior. There was dilatation in the lateral ventricle of the brain and the choroid plexus was depressed. There was no relationship between mass and

Correspondence: Ebru TAŞTEKIN

Trakya Üniversitesi, Tip Fakültesi, Patoloji Anabilim Dal, EDİRNE,TURKEY

E-mail: ebrutastekin@hotmail.com Phone: +90 5326003001 
vascular system in Doppler USG. Medical abortion was performed at 30th week of gestation and the fetus was sent to the pathology laboratory for a complete medical autopsy.

Macroscopically whole body parts of the male fetus had a striking oedema. There were massive pleural and peritoneal effusions on dissection of peritoneal and pleural cavities. The left and right main bronchus and their relationships with mass were evaluated. The left lung was enlarged with dimensions of $12 \times 11 \times 7 \mathrm{~cm}$, filling the entire thoracic cavity. It had cystic dilated structures of various size (Figure 1). The heart was displaced to the right side and the right lung was compressed and atrophied with dimensions of $1.5 \times 1.3 \times 1 \mathrm{~cm}$. Massive fetal oedema was present due to compression of both vena cava inferior and superior by the huge mass of the left lung. Thus, hydrops fetalis was caused by a non-immune reason, which was later also supported by the absence of maternal antibodies.

Microscopically, the left lung mass showed dilated bronchiole-like structures that were lined by ciliated columnar cells without any intervening mucinous epithelial cells. The sub-epithelial stroma between the cystic spaces contained thin, interrupted bands of smooth muscle fibers and elastic connective tissue without any cartilage plates (Figure 2A,B). Immunohistochemically dilated cystic structures showed positive staining for CK7 and TTF1 and subepithelial stroma revealed SMA positive smooth muscle fibers (Figure 3). Other fetal tissue and organs showed massive oedema and immaturity development concordant with the gestational age. The diagnosis was CPAM, type II, according to the modified Stocker's classification (3).

\section{DISCUSSION}

Cystic malformation of the lung is an unusual congenital lesion characterized by cystic spaces of various sizes composed of airway or alveolar-like structures (6). CPAM was first described by Ch'in and Tang in 1949 (1). CPAM is generally a unilateral lesion of one lobe and represents about $25 \%$ of all congenital lung lesions (5). The lesion consists of cysts and solid airless tissue with no cartilage in the wall. It may affect the pulmonary lobes partially or entirely (9).

Congenital pulmonary airway malformation is a hamartomatous, dysplastic developmental abnormality of the lung. It shows hamartoma, dysplasia or tumorous features. There is a putative differentiation from proximal to distal with type 0 originating from the trachea and bronchi and type 4 is originating from the acinus. It is apparent that narrowing or obliteration of the bronchial lumen is a common pathological feature most of the time. Bronchial
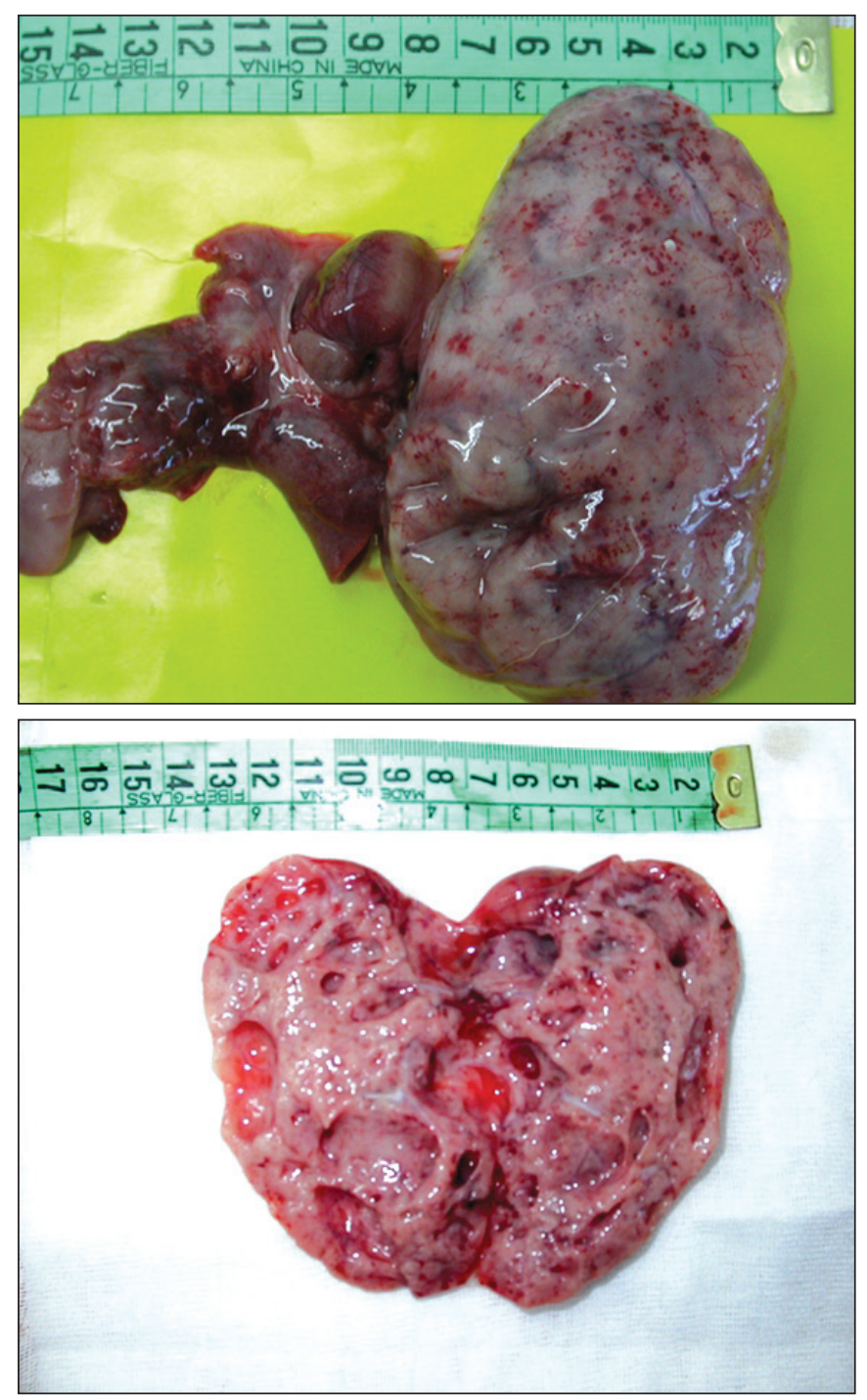

Figure 1: Macroscopic appearance of congenital pulmonary airway malformation.

atresia may especially cause this morphology. The primary bronchial atresia, bronchial segmental disability, pause in the development of the fetal lung, parenchymal differential disability, and dysplastic bronchopulmonary tissue are generally seen at 5-7th weeks of gestation (9). Abnormal Hoxb-5 regulation causes specific alterations in airway branching. Normal lung tissue does not express significant levels of Hoxb-5 protein, while the adjacent CCAM with abnormal and immature airway express the high levels of Hoxb-5. The abnormal expression of this Hox gene could be associated with the development of aberrant branching patterns in BPS and CCAM (10).

Congenital pulmonary airway malformation classification scheme has been revised in 2002 by Stocker and categorized them as: type 0, trachea-bronchial; type 1, bronchial/ 


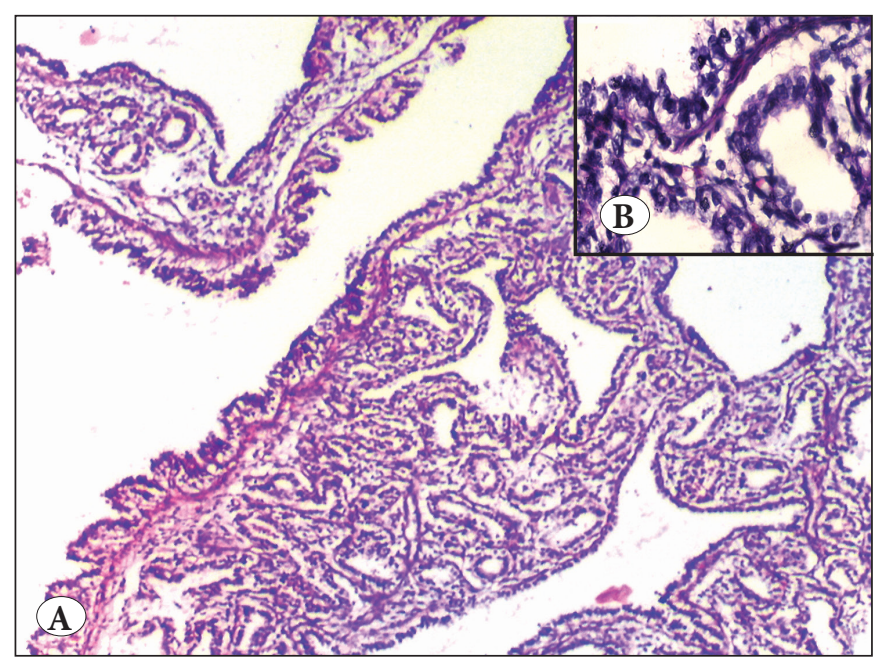

Figure 2: Microscopic appearance of congenital pulmonary airway malformation. A) Dilated bronchiole-like structures of various sizes were seen $(\mathrm{H} \& \mathrm{E} \times 50)$, B) Dilated bronchiole-like structures were lined with ciliated columnar cells without any intervening mucinous epithelial cells (H\&E x400).

bronchiolar; type 2, bronchiolar; type 3, bronchiolar/ alveolar duct; and type 4, distal acinar (16) (Table I).

The prenatal rate of detection of lung cysts at the routine $18-20$ th week scan is almost $100 \%$ and may be the most common example of actual presentation. Late pregnancy diagnosis of CPAM is less sensitive. Once a cystic lung lesion is detected on ultrasound, the location, volume, size, macrocystic or microcystic classification, and blood supply should be evaluated (11).

Serial prenatal sonographic examinations are important for helping to determine the prognosis and necessity for possible intrauterine treatment in patients with CPAM. The prognosis is highly variable and depends on the presence of fetal hydrops and the size of the mass (12).

Hung-wen Chen et al. (13) proposed an algorithm for practical management of patients with CPAM. They suggested that if prenatal ultrasonographic screening reveals a suspicious fetal lung lesion, a series of ultrasonographic examinations should be planned to evaluate the size, content (microcystic, macrocystic or solid) and distribution of the lesion. Fetal therapies such as needle aspiration, catheter shunt placement and fetal surgical resection can be applied. The majority of these lesions will regress or become normal echoic in late pregnancy.

The two major factors affect the management after the birth: the timing of respiratory decompansation and the presence of associated complications. Most cystic lesions can be resected with thoracic surgery (at the age of 3-6) (14).
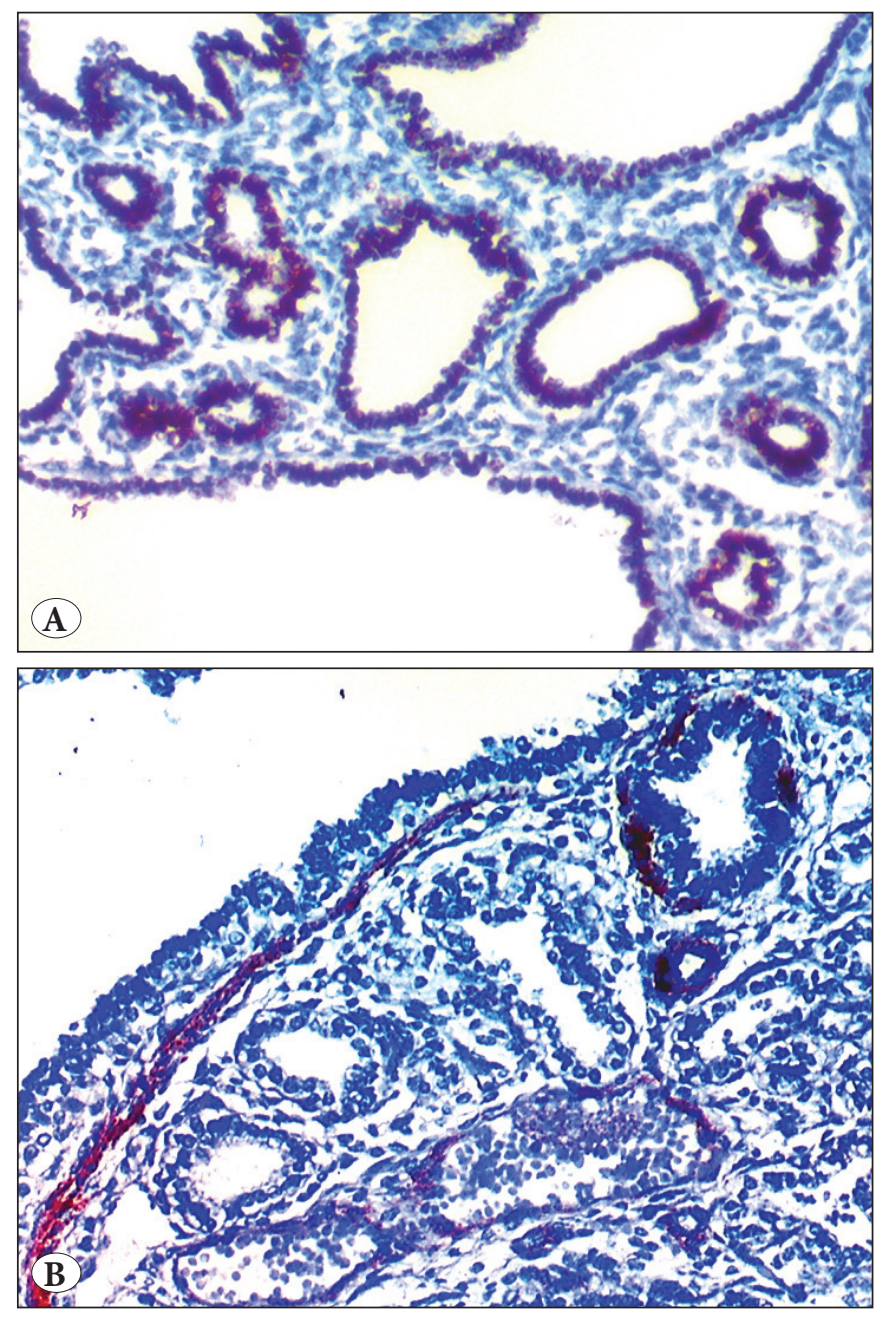

Figure 3: Immunohistochemically, columnar cells of dilated cystic structures showed positive staining for TTF1 (A) and SMA (B) positive smooth muscle fibers in the subepithelial stroma.

Sometimes recurrent pulmonary infections with severe respiratory decompansation can develop in an asymptomatic one month-old patient. Although small asymptomatic lesions can regress, there has been an increasing number of reports of malignancy associated with CPAM over the last decade, which cannot be ignored. These associated neoplasms consist mainly of pleuropulmonary blastoma in infants and young children, and bronchoalveolar carcinoma in older children and adults. Type 4 CPAM is accepted by most authors as type 1 pulmonary blastoma (15). Other cystic or pseudocystic lung lesions include post-infarction peripheral cysts resulting from intrauterine pulmonary artery thrombosis. The cysts have also been noted in Down's syndrome. Air-filled cysts within the interstitium are features of acute and persistent interstitial pulmonary emphysema, and limited to the interlobular septa. Fluidfilled cysts of congenital pulmonary lymphangiectasia 


\begin{tabular}{|c|c|c|c|c|c|}
\hline 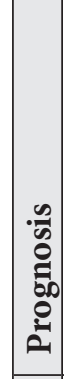 & 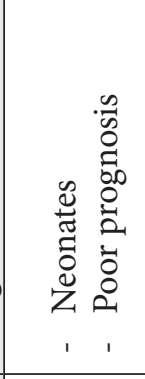 & 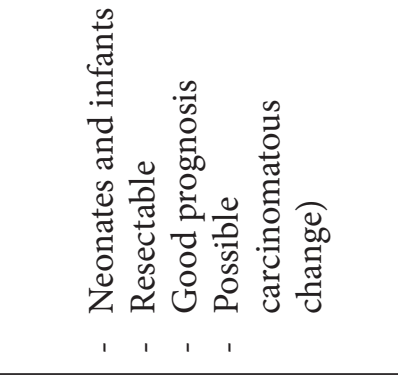 & 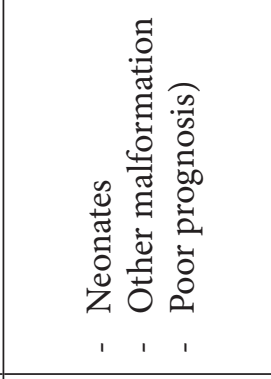 & 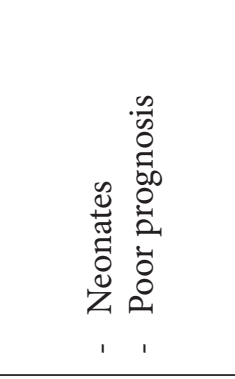 & 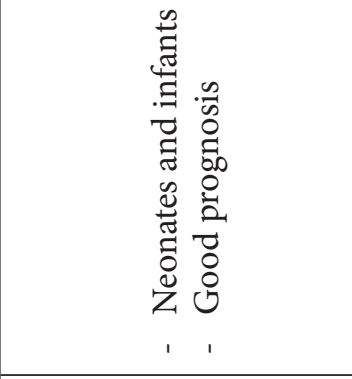 \\
\hline 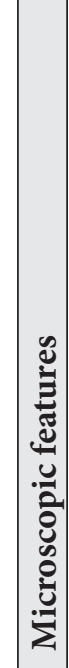 & 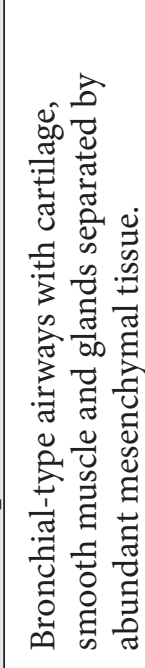 & 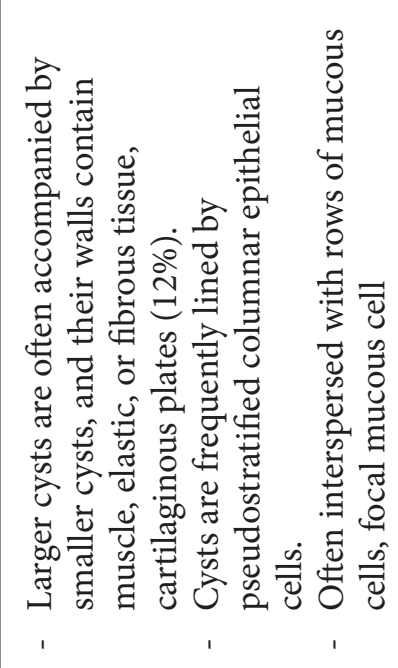 & 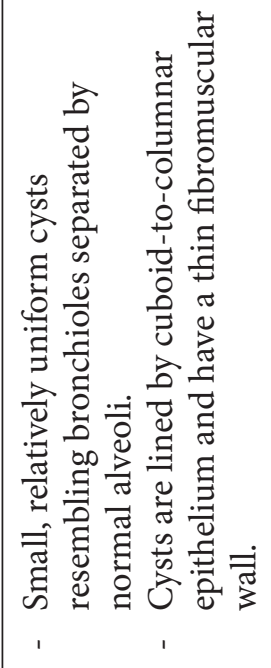 & 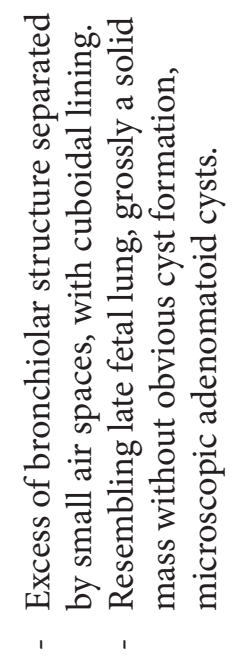 & 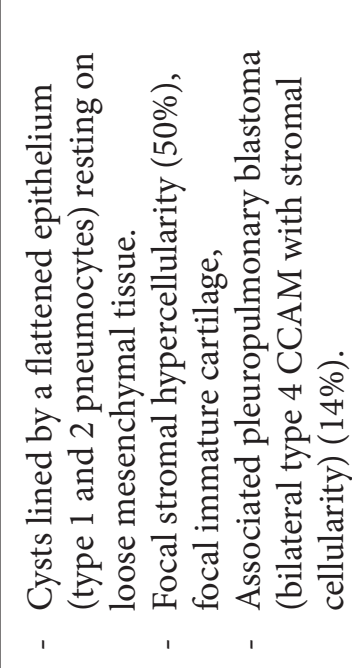 \\
\hline 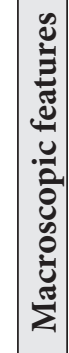 & 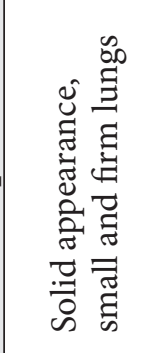 & 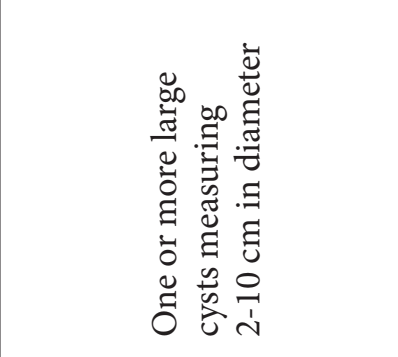 & 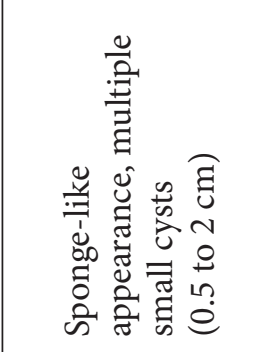 & 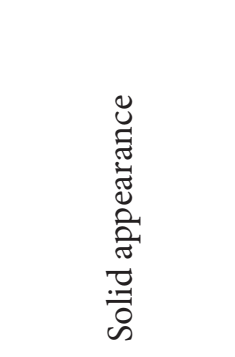 & 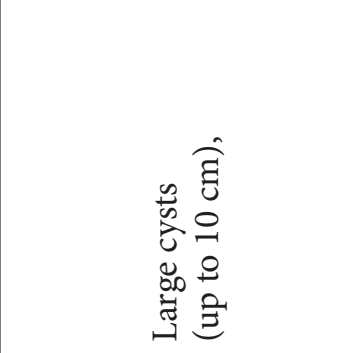 \\
\hline 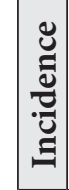 & 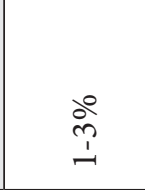 & $\begin{array}{l}\text { oे } \\
\hat{0} \\
0 \\
0\end{array}$ & $\begin{array}{l}\text { î } \\
\text { î } \\
\text { อे }\end{array}$ & in & 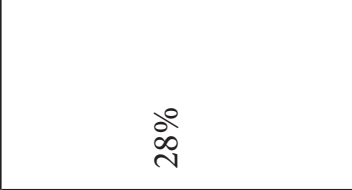 \\
\hline ह & 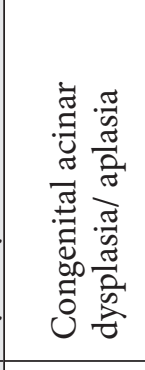 & 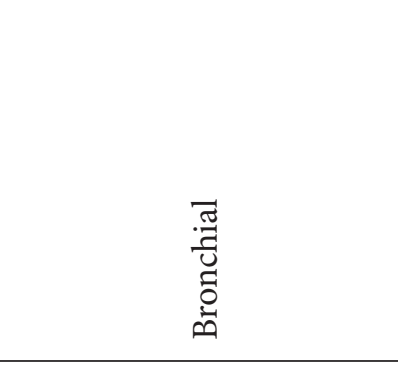 & 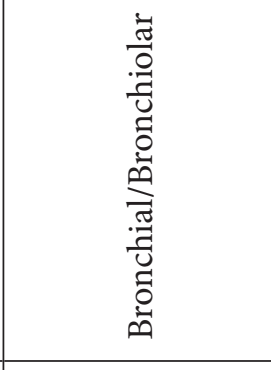 & 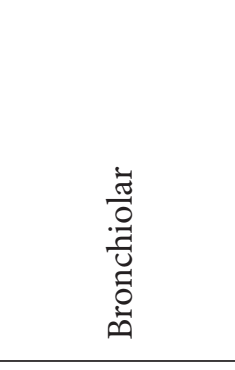 & 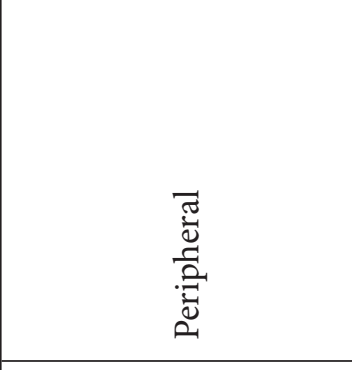 \\
\hline 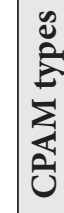 & 产 & 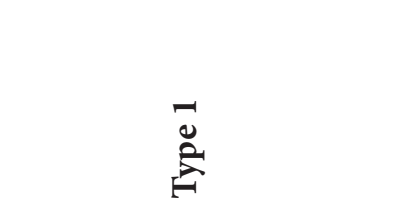 & ڤ్ & 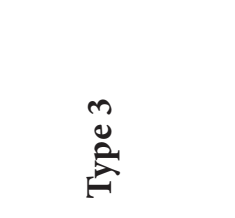 & : \\
\hline
\end{tabular}


are present within the interlobular septa, and extend laterally from the septa beneath the pleura. Congenital pulmonary lymphangiectasia is also frequently associated with congenital malformations of the heart. Bronchogenic cysts are rarely seen in infants, and are solid lesions usually separate from the lung. Extralobar sequestrations are also unaerated lesions separate from the lung and occasionally found within or beneath the diaphragm. Intralobar sequestrations are usually acquired lesions (through infection), and may display air- or fluid-filled cysts, representing re-epithelialized post-infectious abscesses. The infantile lobar emphysema, one of the most common pulmonary lesions in infants and children, is not cystic but simply the over inflation of a segment of lung (16).

Congenital pulmonary airway malformation is a quite rare malformation of fetus. In our case, fetal left lung was larger than that of a stillborn term fetus. The compression of large vessels and the heart was the cause of hydrops fetalis. With these clinical and laboratory findings, the present case is a very good example of non-immune hydrops fetalis associated with CPAM type 2 . Thus prenatal clinical and ultrasonographic follow-up during pregnancy is very important for the early diagnosis of such congenital abnormalities.

\section{REFERENCES}

1. Cha I, Adzick NS, Harrison MR, Finkbeiner WE. Fetal Congenital cystic adenomatoid malformations of the lung: A clinicopathologic study of eleven cases. Am J Surg Pathol. 1997; 21:537-44.

2. Balkan ME, Taştepe I, Pak I, Kapucuoglu N, Unlu M, Ogun D. Konjenital kistik adenomatoid malformasyon. Turk Patoloji Derg. 1992; 8: 49-53.

3. Ch'in KY, Tang MY. Congenital adenomatoid malformation of one lobe of a lung with general anasarca. Arch Pathol (Chic). 1949; 48:221-9.

4. Stocker JT, Mani H, Husain AN. The respiratory tract. In: Stocker JT, Dehner LP. editors, Pediatric pathology. 3rd ed. Philadelphia: Lippincott/Williams \& Wilkins, 2011; 441-515.
5. Gilbert-Barness E. Respiratory system; In: Gilbert-Barness E, editor. Potter's pathology of the fetus and infant. St. Louis: Mosby; 1997. 741-6.

6. Miller R, Sieber WK, Yunis EJ. Congenital adenomatoid malformation of the lung. A report of 17 cases and review of the literature. Pathol Annu. 1980; 15:387-407.

7. Davenport M, Warne SA, Cacciaguerra S, Patel S, Greenough A, Nicolaides K. Current outcome of antenatally diagnosed cystic lung disease. J Pediatr Surg. 2004; 39:549-56.

8. Langston C. New concepts in the pathology of congenital lung malformations. Semin Pediatr Surg. 2003; 12:17-37.

9. Ostör AG, Fortune DW. Congenital cystic adenomatoid malformation of the lung. Am J Clin Pathol. 1978; 70:595-604.

10. Volpe MV, Pham L, Lessin M, Ralston SJ, Bhan I, Cutz E, Nielsen HC. Expression of Hoxb-5 during human lung development and in congenital lung malformations. Birth Defects Res A Clin Mol Teratol. 2003; 67:550-6.

11. Mann S, Wilson RD, Bebbington MW, Adzick NS, Johnson MP. Antenatal diagnosis and management of congenital cystic adenomatoid malformation. Semin Fetal Neonatal Med. 2007; 12:477-81.

12. Barnes NA, Pilling DW. Bronchopulmonary foregut malformations: Embryology, radiology and quandary. Eur Radiol. 2003; 13:2659-73.

13. Chen HW, Hsu WM, Lu FL, Chen PC, Jeng SF, Peng SS, Chen CY, Chou HC, Tsao PN, Hsieh WS. Management of congenital cystic adenomatoid malformation and bronchopulmonary sequestration in newborns. Pediatr Neonatol. 2010; 51:172-7.

14. Lakhoo K. Management of congenital cystic adenomatous malformations of the lung. Arch Dis Child Fetal Neonatal Ed. 2009; 94:F73-6.

15. Ribet ME, Copin MC, Soots JG, Gosselin BH. Bronchioloalveolar carcinoma and congenital cystic adenomatoid malformation. Ann Thorac Surg. 2000; 60:1126-8.

16. Stocker JT, Husain AN. Cystic lesions of the lung in children: Classification and controversies. In: Pathology of the Lung Edited by W. Timens and H.H. Popper. Eur Respir Mon. 2007; 39: 1-20. 